Acta Poetica 24

2003

Roland Barthes

\title{
De la joya a la bisutería (1961)
}

A partir de 1954, Roland Barthes (1915-1980) comenzó a vislumbrar un proyecto semiológico - que lo llevaría a intentar, en la siguiente década, la fundación de una ciencia de los signos que tuviera como matriz la lingüística saussuriana- en numerosos ensayos y artículos periodísticos, al tiempo que profundizaba en un tema particular, la moda, que durante varios años le proveyó evidencias de que un fenómeno social podía estudiarse como sistema de signos. Fruto de esos años será su primer curso en la École Pratique des Hautes Études (1962-63), cuyo título fue: "Inventario de los sistemas contemporáneos de significación: sistemas de objetos (vestimenta, alimentación y alojamiento)", y entre cuyos alumnos se contó a Jean Baudrillard.

Como bien se sabe, aquel proyecto de una semiología fundada en la lingüística fracasó. No así la vertiente de la semiología literaria que el propio Barthes caracterizó en su discurso de ingreso al Collège de France (1977), como una semiología del texto que sería al mismo tiempo desconstrucción de la lingüística -y una escritura tal como él la practicara fértilmente en su obra crítica. En esta segunda vertiente, la impronta de la fenomenología francesa fue fundamental. En un ensayo poco conocido, publicado en 
Belgrado, "Nuevos senderos de la crítica literaria en Francia” (1959), Barthes concede a Gaston Bachelard la mayor importancia dentro de la crítica literaria francesa, y reconoce el valor de su aportación literaria: "la crítica de Bachelard es generosa, ayuda a producir en la interioridad del propio cuerpo el movimiento de la imaginación poética, que es un movimiento esencialmente liberador".

Aunque con el decurso de los años Barthes se alejó de la fenomenología bachelardiana conforme fincó cada vez más en la crítica cultural cuyo modelo irresistible era Bertolt Brecht (el autor fundamental de sus años de formación como crítico teatral), el ensayo que a continuación traduzco muestra cómo Barthes acogió en algún momento la fenomenología poética de Bachelard como procedimiento heurístico, e intentó darle cierta historicidad, de acuerdo con la búsqueda que el incipiente semiólogo se planteara: estudiar no sólo la estructura sino el movimiento. "De la joya a la bisutería” se enlista con los varios ensayos que el escritor publicó sobre el tema de la moda, y que abrieron camino a la publicación del libro El sistema de la moda (1967).

"De la joya a la bisutería" fue publicado originalmente en la revista Jardin des arts, en abril de 1961.

Nota y traducción de Jaime Moreno Villarreal

Durante largo tiempo, durante siglos y quizá milenios, la joya fue esencialmente una sustancia mineral; ya fuese diamante o metal, piedra preciosa u oro, provenía siempre de las profundidades de la tierra, de ese corazón a la vez sombrío y abrasado del que no avistamos más que sus productos enfriados y endurecidos; por su origen, en suma, la joya era un objeto infernal extraído, mediante trayectos costosos y a menudo sangrientos, de esas cavernas inferiores donde la imaginación mítica de la humanidad depositó a la vez a los muertos, los tesoros y las faltas. 
Extracto del infierno, la joya se convirtió en su símbolo, tomó de él su rasgo fundamental: la inhumanidad. Como piedra (ya que de las piedras proviene buena parte de las joyas) era, ante todo, dureza; la piedra ha pasado siempre por ser la esencia misma de la cosa, del objeto irremediablemente inanimado; la piedra no es la vida ni la muerte, es la inercia, la terquedad de la cosa por no ser más que ella misma: es lo inmóvil infinito. De aquí que la piedra sea lo despiadado. El fuego es cruel, el agua taimada; la piedra es la desesperación de lo que jamás vivió ni vivirá jamás, de lo que se resiste obstinadamente a toda animación. Durante muchísimo tiempo la joya tomó de su origen mineral este primer poder simbólico: el de manifestar un orden tan inflexible como el de las cosas.

Asimismo, la imaginación poética de la humanidad concibió piedras conmutables por la usura, piedras nobles, venerables y vivas a pesar de todo, puesto que envejecen. El diamante, que es una quintaesencia de la piedra, está más allá del tiempo: por ingastable e incorruptible, su limpidez forma la imagen moral de la más mortífera de las virtudes: la pureza. Sustancialmente, el diamante es puro, limpio, aséptico casi; pero mientras que hay purezas tiernas y frágiles, por ejemplo la del agua, hay también purezas estériles, frías, filosas; si la pureza es la vida, puede también ser lo inverso, la infecundidad; el diamante es como el hijo estéril de la tierra profunda: no produce, es incapaz de transformarse en podredumbre, en humus, es decir en germen.

Y, no obstante, seduce. Duro, límpido, dispone de una tercera cualidad simbólica: brilla. Hélo aquí incorporado a un tema mágico y poético nuevo, el de una sustancia paradójica, a la vez ígnea y fría: no es sino fuego, y sin embargo no es si no hielo. Este fuego frío, este brillante mordaz que nada dice, ¡qué símbolo establece para la totalidad del orden mundano de las vanidades, de las seducciones sin contenido y de los placeres sin autenticidad! Durante siglos, la humanidad cristiana re- 
sintió vivamente (mucho más que nosotros, hoy) la oposición entre el mundo y la soledad; por sus brillos y frialdad, el diamante era el mundo, ese orden aborrecido y fascinante de ambiciones, lisonjas y engaños, que tantos de nuestros moralistas condenaron - probablemente para describirlo mejor.

¿Y el oro con el que también se confeccionaban las joyas? Aunque procedente de la tierra y del infierno, pues primero fue mineral o pepita, el oro es una sustancia más intelectual que simbólica; sólo fascina en el seno de ciertas economías comerciales; carece de realidad poética, o la tiene muy escasa, sólo se le evoca para señalar cuánto la mediocridad de su sustancia (metal blando y amarillento) contrasta con la amplitud de sus efectos. Pero en cuanto signo, iqué poderío! Pues es nada menos que el signo por excelencia, el signo de todos los signos, el valor absoluto dotado de todos los poderes, incluidos los que usufructuaba la magia: ¿qué no puede apropiarse de todo, bienes y virtudes, vidas y cuerpos?, ¿qué no puede convertirlo todo en su contrario, humillar y elevar, envilecer y glorificar? La joya participó durante largo tiempo de este poder del oro. Y aún más: en la medida en que repentinamente dejó de ser amonedable y utilitario, una vez que se retiró de todo orden práctico, ese oro puro cuyo uso como que se cerró en sí mismo, se convirtió en un oro superlativo, en riqueza absoluta: la joya se convirtió entonces en el concepto mismo del precio; quien la lleva, la porta como una idea, la de un poder terrible al que le basta con ser visto para quedar confirmado.

Ni duda cabe de que la joya, en el fondo, ha sido durante largo tiempo un signo de súper-potencia, es decir de virilidad (tan sólo recientemente y bajo la influencia puritana del traje cuáquero, que es el origen de nuestro traje masculino, los hombres dejaron de portar joyas). ¿Por qué entonces, entre nosotros se ha asociado a la joya tan constantemente con la mujer, con sus poderes y sus maleficios? Esto se debe a que pron- 
to el hombre delegó en la mujer la exhibición de su propia riqueza (algunos sociólogos explican así el origen de la moda): la mujer da testimonio, poéticamente, de la riqueza y el poder del marido. Como siempre en la sociedad humana, ocurre que un motivo de base se inviste muy rápido de significaciones, de símbolos y efectos inesperados. Así, la exposición primitiva de la riqueza se halló penetrada por toda una mitología de la mujer: mitología aún infernal, por lo demás, pues en ella la mujer se pierde por la posesión de las joyas, y el hombre se condena por esa mujer portadora de las mismas joyas por las que se vendió. Mediante la cadena de las joyas, la mujer se entrega al diablo, y el hombre se entrega a la mujer transformada en piedra preciosa y dura. No hay que suponer que este simbolismo a la vez prosaico y espiritual —es decir ingenuo, en sumapertenece sólo a las épocas bárbaras de Occidente: por ejemplo, la sociedad del Segundo Imperio se embriagó y enloqueció toda por el poder de las joyas, por esa suerte de conductividad de la Falta que ha sido durante largo tiempo casi una propiedad física del diamante y el oro: Nana, de Zola, es verdaderamente el canto grandioso y furioso de una sociedad que se aniquilaba en una doble destrucción, una doble devoración podría decirse: donde la mujer es al mismo tiempo devoradora de hombres y de diamantes.

En nuestros días, semejante mitología no ha desaparecido del todo: aún existen los grandes joyeros y un mercado mundial de diamantes, y aún ocurren los robos de joyas célebres. Pero el tema infernal está visiblemente en decadencia. En primer lugar, porque la mitología de la mujer ha cambiado: en la novela, en el cine, la mujer es cada vez menos fatal, ya no destruye al hombre; ya no se la puede inmovilizar, inanimar, hacer de ella un objeto precioso y peligroso: se ha sumado al orden humano. Y por otra parte las joyas, las grandes joyas míticas ya casi no se usan; son valores históricos en asepsia, han sido embalsamadas, se han escindido del cuerpo femeni- 
no, están condenadas a la caja fuerte. En suma, la moda $-\mathrm{y}$ esto lo dice todo- no sabe ya de joyas, solamente de bisutería.

Ahora bien, la moda, lo sabemos, es un lenguaje: a través de ella, a través del sistema de signos que la constituye, por frágil que parezca, nuestra sociedad - y no solamente la sociedad femenina- expone y comunica su ser, dice lo que piensa del mundo; además, tal como en la sociedad antigua la joya expresaba de raíz su naturaleza esencialmente teológica, del mismo modo la bisutería actual, tal como la vemos en las tiendas y en las revistas de la moda, prolonga, expresa y significa nuestro tiempo: en una palabra, podríamos decir que, procedente del mundo ancestral de la falta, la pieza de bisutería se ha laicizado.

Esta secularización ha alcanzado en primer término, y por demás visiblemente, la sustancia misma de las joyas: ya no sólo se hacen de piedra o de metal, sino también de materias frágiles y suaves, como el vidrio o la madera. Además, las joyas ya no tienen la encomienda invariable de proclamar un precio, por decirlo así, inhumano: las hallamos en metal vulgar y en vidrio barato; y cuando imitan alguna sustancia preciosa, como el oro o las perlas, lo hacen sin bochorno: el símil, que se ha convertido en una característica de la civilización capitalista, ya no es más un procedimiento hipócrita para hacerse pasar por rico pagando barato; se expone con franqueza, no intenta engañar sino solamente conservar las cualidades estéticas de la materia imitada. En síntesis, hay una liberación general de la joya: su definición se amplía y actualmente constituye un objeto, si cabe decirlo, libre de prejuicios: multiforme, multisustancial, de usos infinitos, ya no sometido a la ley del alto precio ni a la del uso exclusivo, celebratorio, casi sagrado: la joya se ha democratizado.

Esta democratización acarrea, desde luego, la compensación de un nuevo sello de valor. En tanto que la riqueza regía 
la rareza de la joya, no podía ser juzgada más que por su precio (el de su materia y el de su trabajo); pero una vez que casi todo el mundo puede procurarse una cosa, una vez que la obra se convirtió en producto, hubo que someterla en nuestras sociedades, democráticas pero aún diferenciadas, a una discriminación de otro orden: el del gusto, del cual la moda es precisamente juez y protectora. Así, disponemos en la actualidad de joyas de mal gusto; y cosa paradójica, lo que define el mal gusto de una pieza de bisutería es curiosamente esa proclamación que antes fundaba el prestigio y la magia de la joya: su precio excesivo. No solamente la bisutería demasiado rica y sobrecargada está desacreditada, sino que a la inversa, para que una joya cara sea de buen gusto, es necesario que su riqueza sea discreta, sobria, visible sin lugar a dudas, pero sólo a los ojos de los iniciados.

¿Qué es entonces el buen gusto, hablando de una joya de hoy en día? Simplemente esto: que la pieza de bisutería, por poco que cueste, se discierna en conexión con el conjunto del traje, que se someta a ese valor esencialmente funcional que es el estilo. La novedad del asunto, si se quiere, es que la joya ya no está sola; es un término de una relación que reúne de una vez el cuerpo, la vestimenta, el accesorio y la circunstancia; forma parte de un conjunto, y ese conjunto no es ya fatalmente ceremonial: el gusto puede ejercerse en todas partes - en el trabajo y en el campo, por la mañana y durante el invierno-, y la bisutería lo obedece; ya no es más el objeto exclusivo, fulgurante y mágico concebido para ornar, es decir para hacer valer a la mujer; más humilde y más activo, en lo sucesivo forma parte de la vestimenta, ha entrado en relación de igual a igual con una tela, con un corte y con cualquier otro accesorio.

Ahora bien, en lo específico, su reducido tamaño, su índole finita y su sustancia misma ajena a la fluidez de los tejidos, hacen encajar a la pieza de bisutería en un apartado de la moda que se ha convertido casi en el alma de la economía general 
del vestido: el detalle. Era inevitable que, al hacer del gusto el producto de un conjunto sutil de funciones, la moda concediera un poder creciente a la simple presencia de un elemento, por menudo que fuera, sin conceder mayor importancia a su magnitud física; de ahí el extremo valor, en la moda actual, de todo lo que a pesar de un muy escaso tamaño modifique, armonice y anime la estructura de una vestimenta, y que se lo denomine precisamente (pero a partir de ahora con mucha deferencia) una nadería. La pieza de bisutería es una nadería, pero una nadería de la que emana una energía muy grande: por lo general poco costosa, vendida en modestas "boutiques" y ya no en los templos de la joyería, de materia varia, de inspiración libre (a menudo incluso exótica), en suma depreciada en sentido literal, en cuanto a su ser físico, la pieza de bisutería más modesta permanece como el elemento vital de un atavío personal porque señala en él la voluntad de orden, de composición —en síntesis, digamos, de inteligencia: análoga a esas sustancias mitad químicas, mitad mágicas que actúan con fuerza mayor conforme se aplican en dosis infinitesimales, la joya de bisutería reina sobre la vestimenta ya no por ser absolutamente preciosa, sino porque concurre de manera decisiva a hacerla significar: lo que de aquí en adelante se ha hecho precioso es el sentido de un estilo, y ese sentido depende no de cada uno de los elementos, sino de la relación entre ellos, y en dicha relación el término desprendido (un bolso, una flor, una mascada, una joya de bisutería) es lo que posee el último poder de significación; verdad no solamente analítica sino poética: ese enorme trayecto que conduce, a través de los siglos y las sociedades, de la joya a la bisutería, es el mismo itinerario que transformó las piedras frías y lujosas del universo baudeleriano en esos bibelots, bisuterías y naderías en los que Mallarmé supo contener toda una metafísica del nuevo poder del hombre para hacer significar las cosas ínfimas. 